\title{
Knowledge, attitudes and practices of parents on child sexual abuse and its prevention in Shinyanga district, Tanzania
}

\author{
FREDRICK M. MLEKWA ${ }^{1 *}$, TUMAINI NYAMHANGA ${ }^{2}$, PHILLIPO L. CHALYA ${ }^{3}$ and DAVID URASSA ${ }^{2}$ \\ ${ }^{1}$ Department of Obstetrics \& Gynaecology, Shinyanga Regional Referral Hospital, Shinyanga, Tanzania \\ ${ }^{2}$ Muhimbili University of Health and Allied Sciences, Dar es Salaam, Tanzania \\ ${ }^{3}$ Catholic University of Health and Allied Sciences-Bugando, Mwanza, Tanzania
}

\begin{abstract}
Background: The role of parents in preventing child sexual abuse in the community in low-and-middle income countries has not been adequately emphasized. The objective of this study was to assess parents' knowledge, attitudes and practices on child sexual abuse and its prevention in Shinyanga district, Tanzania in order to strengthen child protection.

Methods: This was a cross-sectional study conducted during July 2015. Multistage cluster sampling technique was employed to obtain study participants from a list of sampling frame. Parents with children below 18 years old were randomly selected to form a study population. A quantitative technique using structured questions was used to assess parents' knowledge, attitude and practices about preventing child sexual abuse.

Results: A total of 384 respondents were included in the study. The majority (95.6\%) of respondents had high knowledge regarding prevention of child sexual abuse. Majority (98.7\%) of the respondents had positive attitudes on preventing child sexual abuse. However, only about a quarter (27.3\%) of respondents had good practices on protection and prevention of child sexual abuse.

Conclusion: Knowledge and attitudes of parents on child sexual abuse prevention was high in the study area. However, the practices of parents on child sexual abuse prevention were poor. Therefore, a public education programme is needed for parents, with the ultimate aim of protecting children from the preventable harm and trauma of sexual abuse in rural communities of Tanzania.
\end{abstract}

Keywords: Child sexual abuse, knowledge, attitudes, practice, parents, Tanzania

\section{Introduction}

Child sexual abuse (CSA) is a global public problem (WHO, 2003). It is defined as the involvement of a child in sexual activity that he/she does not fully comprehend and is unable to give informed consent to, or for which the child is not developmentally prepared (WHO, 2014).Other recent definitions of CSA have included the array of sexual activities such as fondling, inviting a child to touch or be touched sexually, intercourse, rape, incest, sodomy, exhibitionism, involving a child in prostitution or pornography, or online child luring by cyber predators (Putnam, 2003; Wolak et al., 2008).

The World Health Organization has estimated that 73 million boys and 150 million girls under the age of 18 years had experienced various forms of sexual violence in their life time (WHO, 2002). Highest prevalence (34.4\%) of child sexual abuse is in Africa (Wihbey et al., 2013). The prevalence is higher among female than male children. A review of studies from both high- and middle-income countries has shown that seven to $36 \%$ of females and three to $29 \%$ of males reported being victims of sexual abuse during their childhood (Miller et al., 2007). There are only a few published studies on child sexual abuse in Africa, with the exception of South Africa (Lalor, 2004). However, a number of studies have reported that approximately $5 \%$ of the reported cases have had penetrative sexual abuse during their childhood (Lalor, 2004). A study in Tanzania indicated that $30 \%$ of girls and $14.3 \%$ of boys have experienced at least one sexual abuse incidence prior to the age of 18 (Garcia-Moreno et al., 2005).In Sub-Saharan Africa, the most frequently reported reasons for sexual abuse in children include rapid social change, AIDS/HIV avoidance strategies and patriarchal nature of society; and that it is most frequently perpetrated by family members, relatives, neighbours or others known to the child (Lalor, 2004).Studies in South Africa, Zimbabwe and Tanzania have indicated that childhood sexual and physical abuse is high and shows

${ }^{*}$ Correspondence E-mail: Fredrick M. Mlekwa: marwillo@yahoo.com 
strong relationships with a range of sexual risk behaviors, including age at first sex, alcohol and drug, forced sex and ever being hurt by a partner. Individuals abused in childhood comprise between 6 and $29 \%$ of young adult men and women living in these South Africa, Zimbabwe and Tanzania and constitute a population at high risk of HIV infection (Ritchter et al., 2014).

There is dearth of data on child sexual abuse in Tanzania. However, it is perceived to be increasing (Kisanga et al., 2010, 2013; Abeid et al., 2014) as a result of AIDS sufferers' attempts to "cleanse" themselves (Lalor, 2004). In Tanzania, most studies on factors influencing child sexual abuse to have been conducted in urban Tanzanian settings (Laiser et al., 2009, 2011; Kisanga et al., 2010; Muganyinzi et al., 2011; Abeid et al., 2014), hence information on rural community is limited.

It is believed that parents are important actors in protecting their children from any kind of violence including sexual abuse. Knowledge, attitudes and practices with responsible parenting are instrumental in prevention of child sexual abuse. However, few studies have been conducted in Tanzania, on the community perceptions (Abeid et al., 2014) or on the role of parents in prevention of child sexual abuse (Mathoma et al., 2006). Therefore, a need to conduct a thorough research on assessing parents' knowledge, attitudes and practices about preventing child sexual abuse is important. The objective of this study was to assess parents' knowledge, attitudes and practices about preventing child sexual abuse in Shinyanga district, Tanzania in order to strengthen child protection.

\section{Methods and Materials}

\section{Study site and design}

This was a cross-sectional study conducted in Shinyanga district in July 2015. Shinyanga district is divided into 4 divisions, 26 wards and 117 villages with a population of 450,000 people and of 580 hamlets. A $50 \%$ of the 26 wards were randomly selected and 2 villages in each selected wards were randomly selected for the study. A quantitative technique using structured questions having both open and closed ended questions was used to assess parents' knowledge, attitude and practices about preventing child sexual abuse in the community.

\section{Sampling and data collection}

Parents with children below18 years old who were randomly selected and were residents of the study areas formed a study population. Nuclear, single and adopted families were included as well as extended family. Parents who were not residents of Shinyanga district (parent visitors) during the period of data collection were excluded. The sample size $(n)$ for all respondents was calculated using formula by Cochran (1977). A minimum sample size was estimated to be 384 parents. Multistage cluster sampling technique was employed to obtain a required number of the study population.

A sampling frame from the list of wards was prepared and used for drawing sample. From sampling frame, study units were sampled through simple random method until the required sample of 384 parents of children under the age of 18 years was obtained. Information on parent's knowledge, attitudes and practices about child sexual abuse was collected using a structured questionnaire with both open and closed ended questions.

\section{Data analysis}

Data cleaning was done manually and later data entry was done using Statistical Package for Social Science (SPSS) version 20. The descriptive statistics was computed, association and comparisons of variables was done using Fishers exact test for categorical variables. $\mathrm{P}$ value of $<0.05$ was considered significant to provide evidence of significant differences or associations on study. Statistical association using Chi-square test was made to determine the parent's knowledge, attitude and practices about preventing child sexual abuse at $5 \%$ level of significance. Furthermore, variables were included in analysis when $\mathrm{p}<0.05$ and data analysis was presented in tables, texts and charts. 
Knowledge of parents' role on strategies for preventing child sexual abuse were measured on both open and closed ended questions. A correct answer on closed ended question was scored one point and incorrect answer was scored o point and each correct mentioned step was scored one point. Scores varies from 0 to 10 points. Knowledge scores were used to decide cut off points in percentages as a poor (below 60\%), fair (60-70\%) and a high ( $80 \%$ and above). These was used to classify three levels of knowledge about strategies for preventing child sexual abuse in the community according to Bloom's cut off point. Furthermore, the high and fair could be merged to good knowledge.

Parents' attitudes about preventing child sexual abuse was measured by 10 Likert's scale-type statement using four points from strongly agree to strongly disagree. It had both positive and negative statements and the score for correct and incorrect answers. The scores range from 0 to 30 points. Each score was summed up and a mean score for total attitude calculated and classified into two attitudes level (positive or negative). Parents' practices were measured by questions prepared on a format of questionnaires. The score ranges from 0 to 10 points. The three levels for the practice score were used to classify practice on preventing child sexual abuse in the community. The three levels of practices are: Good practice (above $80 \%$ ), fair practice (60- $80 \%$ ) and poor practice (below 60\%).

\section{Ethical consideration}

Ethical clearance was sought from the Research and Publication Committee of the Muhimbili University of Health and Allied Sciences. The permission to conduct the study was sought from Regional Administrative Secretary of Shinyanga as well as Shinyanga District Executive Director. Study participants were informed on the study purpose as well as rationale and that, participation was voluntary, hence those who were willing to participate in the study signed in the consent form.

\section{Results}

\section{Socio-demographic characteristics of the study respondents}

A total of 384 parents were interviewed. Majority (61\%) of the respondents were aged between 30 and 50 years. Over two-thirds (69.8\%) of the respondents had primary school education. Furthermore, majority of respondents (94.5\%) were peasants, of whom men and women constituted of $92.5 \%$ and $98.3 \%$ of the participants. Most (94.7\%) of the respondents lived in the study area for more than four (4) years (Table 1 ).

Table 1: Socio-demographic characteristic of the study respondents $(n=384)$

\begin{tabular}{lllll}
\hline Characteristic & Response & Male $\mathbf{n}(\%)$ & Female $\mathbf{n}(\%)$ & Total $\mathbf{n}(\%)$ \\
\hline Age group (years) & $<30$ & $19(9.7)$ & $46(24.5)$ & $65(16.9)$ \\
& $30-50$ & $128(65.3)$ & $105(55.9)$ & $233(60.7)$ \\
Education level & $51+$ & $49(25.0)$ & $37(19.7)$ & $86(22.4)$ \\
& None & $37(18.9)$ & $54(28.7)$ & $91(23.7)$ \\
& Primary & $143(73.0)$ & $125(66.5)$ & $268(69.8)$ \\
& Secondary & $14(7.1)$ & $8(4.3)$ & $22(5.7)$ \\
Occupation & College & $2(1.0)$ & $1(0.5)$ & $3(0.8)$ \\
& Peasant/farmer & $182(92.5)$ & $181(98.3)$ & $363(94.5)$ \\
& Miner/business & $6(3.1)$ & $0(0.0)$ & $6(1.6)$ \\
Period of & Cattle herder & $5(2.8)$ & $5(2.7)$ & $10(2.6)$ \\
(years) & Civil servant & $3(1.5)$ & $2(1.1)$ & $5(1.3)$ \\
& 1 & $3(1.5)$ & $3(1.6)$ & $6(1.6)$ \\
& 2 & $4(2.0)$ & $4(2.1)$ & $8(2.1)$ \\
& 2 & $3(1.5)$ & $3(1.6)$ & $6(1.6)$
\end{tabular}




\begin{tabular}{lllll} 
& $4^{+}$ & $186(94.9)$ & $178(94.7)$ & $364(94.7)$ \\
Type of family & Nuclear & $113(57.7)$ & $97(51.6)$ & $210(54.7)$ \\
& Extended & $67(34.2)$ & $66(35.1)$ & $133(34.6)$ \\
& Single & $16(8.2)$ & $22(11.7)$ & $38(9.9)$ \\
& Adopted & $0(0.0)$ & $3(1.6)$ & $3(0.8)$ \\
\hline
\end{tabular}

\section{Knowledge about preventing child sexual abuse among parents}

The majority of the respondents (95.6\%) had high knowledge on preventing child sexual abuse, while $17(4.4 \%)$ were ranked as having poor level of knowledge. More than $85 \%$ of the respondents agreed to have knowledge on prevention of child sexual abuse. Majority (93.8\%) of the respondents agreed that special emphasis of parent's role for preventing CSA should look carefully on children with disabilities; and that for effective CSA prevention parents must review rules and policy of protecting children's right. Relatively few participants (88.5\%) agreed that proper and sustainable intervention on preventing child sexual abuse will remove myths and maintain the basics of nurturing children (Table 2 ).

Table 2: Respondents knowledge on prevention of child sexual abuse $(n=384)$

\begin{tabular}{|c|c|c|c|}
\hline Statements & True $n(\%)$ & False $n(\%)$ & Don't know n(\%) \\
\hline $\begin{array}{l}\text { Parents must take the primary responsibility for } \\
\text { preventing CSA by addressing any questionable } \\
\text { behaviour/risk }\end{array}$ & $357(93.0)$ & $10(2.6)$ & $17(4.4)$ \\
\hline $\begin{array}{l}\text { Prevention of CSA includes avoiding touching and non- } \\
\text { touching behaviour with a child to meet sexual need or } \\
\text { interest }\end{array}$ & $245(89.8)$ & $17(4.4)$ & $22(5.7)$ \\
\hline $\begin{array}{l}\text { Parents have to develop concrete strategies for } \\
\text { preventing CSA in their locality }\end{array}$ & $349(90.9)$ & $10(2.6)$ & $24(6.3)$ \\
\hline $\begin{array}{l}\text { Special emphasis of parents role for preventing CSA } \\
\text { should look carefully on children with disabilities }\end{array}$ & $360(93.8)$ & $8(2.1)$ & $16(4.2)$ \\
\hline $\begin{array}{l}\text { Prevention of CSA in the community require simple clear } \\
\text { and understandable communication language and signs }\end{array}$ & $343(89.3)$ & $15(3.9)$ & $26(6.8)$ \\
\hline $\begin{array}{l}\text { When parents trust each other and speak up together } \\
\text { they can prevent CSA happening in both girls and boys }\end{array}$ & $340(88.5)$ & $19(4.9)$ & $25(6.5)$ \\
\hline $\begin{array}{l}\text { Prevention of CSA is very crucial and should be considered } \\
\text { a priority in the community programs }\end{array}$ & $358(93.2)$ & $13(3.4)$ & $13(3.4)$ \\
\hline $\begin{array}{l}\text { Support, safety and love of parents to their children is a } \\
\text { fundamental for preventing CSA in the community }\end{array}$ & $340(88.5)$ & $11(2.9)$ & $33(8.6)$ \\
\hline $\begin{array}{l}\text { Prevention of CSA promotes a great time for parents to } \\
\text { review rules and policy of protecting children's right }\end{array}$ & $358(93.2)$ & $13(3.4)$ & $13(3.4)$ \\
\hline $\begin{array}{l}\text { Proper and sustainable intervention on CSA will remove } \\
\text { myths and maintain the basics of nurturing kids }\end{array}$ & $340(88.5)$ & $11(2.9)$ & $33(8.6)$ \\
\hline
\end{tabular}

\section{Knowledge level towards preventing child sexual abuse}

Knowledge level was categorised into three groups: low, moderate and high. These were recorded into two variables, namely good (high and fair) and poor knowledge. The respondents who stayed for 4 or more years were reported with statistically higher 351(96.4\%) level of knowledge towards preventing child sexual abuse $(p<0.01)$. There was also difference between types of family and levels of knowledge for preventing child sexual abuse $(p=0.04)$. Age, education level and occupation of the respondent were not significantly associated with the level of knowledge for preventing child sexual abuse.

Table 3: Level of knowledge by respondent's characteristics ( $n=384)$

\begin{tabular}{llll}
\hline Characteristic & Variable & Knowledge, n (\%) & P-value*
\end{tabular}




\begin{tabular}{llllll} 
& & High & Low & Total & \\
\hline Age group (years) & $<30$ & $61(93.8)$ & $4(6.2)$ & $65(100)$ & 0.24 \\
& $30-50$ & $226(97.0)$ & $7(3.0)$ & $233(100)$ & \\
Education level & $51+$ & $80(93.0)$ & $6(7.0)$ & $86(100)$ & \\
& None & $88(94.5)$ & $5(5.5)$ & $91(100)$ & 0.70 \\
& Primary & $256(95.5)$ & $12(4.5)$ & $268(100)$ & \\
& Secondary & $22(100)$ & $0(0.0)$ & $22(100)$ & \\
Occupation & College & $3(100)$ & $0(0.0)$ & $3(100)$ & \\
& Crop farming & $346(95.3)$ & $17(9.4)$ & $363(100)$ & 0.79 \\
& Mining /business & $10(100.0)$ & $0(0.0)$ & $10(100)$ & \\
& Livestock & $6(100)$ & $0(0.0)$ & $6(100)$ & \\
& farming & & & & \\
Period of stay (years) & Civil service & $5(100)$ & $0(0.0)$ & $5(100)$ & \\
& 1 & $4(66.7)$ & $2(33.3)$ & $6(100)$ & $<0.01$ \\
& 2 & $7(87.5)$ & $1(12.5)$ & $8(100)$ & \\
& 3 & $5(83.3)$ & $1(16.7)$ & $6(100)$ & \\
Type of family & $4+$ & $351(96.4)$ & $13(3.6)$ & $364(100)$ & \\
& Nuclear & $196(93.3)$ & $14(6.7)$ & $210(100)$ & \\
& Extended & $132(99.2)$ & $1(0.8)$ & $133(100)$ & \\
& Single & $36(94.7)$ & $2(5.3)$ & $38(100)$ & \\
& Adopted & $3(100)$ & $0(0.0)$ & $3(100)$ & \\
\hline
\end{tabular}

*P-value for Fisher's exact test

\section{Respondents' attitudes towards child sexual abuse prevention}

Attitude of respondents was determined by asking them to respond to 10 questions which had a total score of 30 points. The results show that 379(98.7\%) of parents had a positive attitude towards parents playing a role in prevention of child sexual abuse. Only $5(1.3 \%)$ had negative attitude towards child sexual prevention. A total of $239(62.2 \%)$ respondents admitted that civil sexual abuse prevention education is very necessary for child sexual abuse prevention. However, $44.8 \%$ of the respondents strongly agreed that prevention of child sexual abuse should be an agenda in routine village meetings. Seventy-one (18.5\%) respondents strongly agreed that child sexual abuse prevention education may induce the child to know too much about sex. Slightly over one-third (36.7\%) of the respondents indicated that parents' can play an important role in preventing child sexual abuse in their locality (Table 4).

Table 4: Respondents attitudes about preventing child sexual abuse $(n=384)$

\begin{tabular}{|c|c|c|c|c|}
\hline Statements & $\begin{array}{l}\text { Strongly } \\
\text { agree } \mathrm{n}(\%)\end{array}$ & Agree $\mathrm{n}(\%)$ & $\begin{array}{l}\text { Disagree } \\
\mathrm{n}(\%)\end{array}$ & $\begin{array}{l}\text { Strongly } \\
\text { disagree } n(\%)\end{array}$ \\
\hline $\begin{array}{l}\text { Child sexual abuse (CSA) prevention } \\
\text { education is very necessary }\end{array}$ & $239(62.2)$ & $126(32.8)$ & $11(2.9)$ & $8(2.1)$ \\
\hline $\begin{array}{l}\text { Parents' can play a big role on preventing } \\
\text { CSA in their locality }\end{array}$ & $141(36.7)$ & $223(58.1)$ & $16(4.2)$ & $2(0.5)$ \\
\hline $\begin{array}{l}\text { CSA prevention education may induce the } \\
\text { child to know too much about sex }\end{array}$ & $71(18.5)$ & $166(43.2)$ & $109(28.4)$ & $38(9.9)$ \\
\hline $\begin{array}{l}\text { It is appropriate to develop CSA prevention } \\
\text { programmes in the local area }\end{array}$ & $119(31.0)$ & $253(65.9)$ & $9(2.3)$ & $1(0.3)$ \\
\hline Appropriate education will help prevent CSA & $116(30.2)$ & $251(65.4)$ & $16(4.2)$ & $1(0.3)$ \\
\hline $\begin{array}{l}\text { It is very important to have one stop centre } \\
\text { for CSA prevention issues }\end{array}$ & $147(36.3)$ & $206(53.6)$ & $27(7.0)$ & $4(1.0)$ \\
\hline $\begin{array}{l}\text { Prevention of CSA should be agenda in the } \\
\text { village meetings }\end{array}$ & $172(44.8)$ & $199(51.8)$ & $10(2.6)$ & $3(0.8)$ \\
\hline $\begin{array}{l}\text { CSA needs concrete strategies on its } \\
\text { prevention }\end{array}$ & $91(23.7)$ & $282(73.4)$ & $11(2.9)$ & $0(0.0)$ \\
\hline $\begin{array}{l}\text { Parents have role in identifying people in the } \\
\text { community who do sexual abuse to children? }\end{array}$ & $126(32.8)$ & $246(64.1)$ & $12(3.1)$ & $0(0.0)$ \\
\hline
\end{tabular}


Community prevention of CSA needs 85(22.1) 268(69.8) 31(8.1) $\quad 0$ (0.0) multisectoral approach

\section{Attitude towards preventing child sexual abuse}

Majority (97.7\%) of the respondents aged 30 to 50 years had positive attitude towards preventing child sexual abuse. Respondents with secondary and college levels of education had more positive attitudes towards preventing child sexual abuse than those with lower levels of education. The respondents who stayed for 5 and above years were reported with higher positive 357(99.4\%) level of attitude towards preventing child sexual abuse. The period of stay was significantly associated with level of attitude for preventing child sexual abuse $(p<0.01)$. The type of family, age, education level and profession of respondent were not statistically significant associated with the level of attitude for preventing child sexual abuse in the study area.

\section{Practices about prevention of child sexual abuse}

The results indicate that $279(72.7 \%)$ of respondents had poor performance regarding practices for prevention of child sexual abuse. Only $27.3 \%$ had good performance regarding the practices. This indicates that practices for prevention of child sexual abuse in the study area are unsatisfactory. Only 34 (39.5\%) of the respondents aged 51 and above had good practices towards preventing child sexual abuse. Respondents with college level of education had more good practices towards preventing child sexual abuse than those with lower education levels. Respondents who were cattle herders had relatively good practices toward preventing sexual abuse compared to other occupation. Only about a quarter (27.3\%) of the respondents who stayed at the community for four or more years had good performance regarding practices for prevention of child sexual abuse (Table 5). Age group $(p<0.01)$, profession $(p=0.02)$ and type of family $(p=0.01)$ were significantly associated with level of practices in preventing child sexual abuse. On the other hand, education level and period of stay of the respondent was not statistically significantly associated with the level of practices for preventing child sexual abuse.

Table 5: Child sexual abuse prevention practices by respondents' characteristics

\begin{tabular}{llllll}
\hline Characteristic & Variable & Practice & & P-value* \\
& & Good & Poor & Total & \\
\hline Age group (years) & $<30$ & $17(26.2)$ & $48(73.8)$ & $65(100)$ & 0.01 \\
& $30-50$ & $54(23.2)$ & $179(76.8)$ & $233(100)$ & \\
Education level & $51+$ & $34(39.5)$ & $52(60.5)$ & $86(100)$ & \\
& None & $25(27.5)$ & $66(72.5)$ & $91(100)$ & 0.52 \\
& Primary & $76(28.4)$ & $192(71.6)$ & $268(100)$ & \\
& Secondary & $3(13.6)$ & $19(86.4)$ & $22(100)$ & \\
Occupation & College & $1(33.3)$ & $2(66.7)$ & $3(100)$ & \\
& Crop farming & $95(26.2)$ & $268(73.8)$ & $363(100)$ & 0.02 \\
& Mining /business & $3(30.0)$ & $7(70.0)$ & $10(100)$ & \\
Period of stay (years) & Livestock farming & $5(83.3)$ & $1(16.7)$ & $6(100)$ & \\
& Civil service & $2(40.0)$ & $3(60.0)$ & $5(100)$ & \\
& 1 & $0(0.0)$ & $6(100)$ & $6(100)$ & 0.17 \\
& 2 & $2(25.0)$ & $6(75.0)$ & $8(100)$ & \\
& 3 & $1(16.7)$ & $5(83.3)$ & $6(100)$ & \\
& 4t & $102(28.0)$ & $262(72.0)$ & $364(100)$ & \\
& Nuclear & $69(32.9)$ & $141(67.1)$ & $210(100)$ & 0.01 \\
& Extended & $25(18.8)$ & $108(81.2)$ & $133(100)$ & \\
& Single & $9(23.7)$ & $29(76.3)$ & $38(100)$ & \\
& Adopted & $2(66.7)$ & $1(33.3)$ & $3(100)$ &
\end{tabular}

*P-value for Fisher's exact test

About two-thirds (63.5\%) of the respondents agreed that they would like to share the information on child sexual abuse prevention with their relatives or peers. Similarly, $62.2 \%$ of respondents 
agreed that children with child sexual abuse should get proper support on prevention and attention from the local leaders. The results indicate that only $8(2.1 \%)$ agreed that they have children who have been sexually abused. Interestingly, only $46.1 \%$ of the parents admitted to tell children not to let someone touch their genitals; while about half $(52.1 \%)$ do restrict children from taking rewards/gifts from unknown people. Moreover, about half (55.7\%) agreed that they conduct family meetings to address CSA prevention. While only $51 \%$ indicated that they would participate in escorting a sexually abused child to get medical or legal services; one third (37.8\%) of the respondents were of the opinion that sexually abused children do not get proper support on prevention from local leaders.

\section{Discussion}

This study has shown about the level of knowledge about preventing child sexual abuse in among rural community of Shinyanga district. The study area has higher knowledge on their role for preventing child sexual abuse. This is in agreement with other studies elsewhere (Wurtele et al., 1992; Babatsikos, 2010) which showed higher level of knowledge for preventing child sexual abuse. The high level of knowledge among parents in the rural area was probably a result of a number of strategies including public education on prevention of child sexual abuse.

In this study, there was a non-significant relationship between knowledge levels among parents with their education level, duration of stay, type of family and occupation. However, public education programmes for preventing child sexual abuse important to update them on their role as parents in preventing child sexual abuse. The majority of the parents in demonstrated positive attitude towards preventing child sexual abuse. Studies in China (Chen \& Chen, 2005; Chen et al., 2007) have also reported similar findings. The possible reasons for higher positive attitude for preventing child sexual abuse in the study is due to the growing evidence of an association between child sexual abuse and HIV/AIDS (Bensley et al., 2000; WHO, 2002). Child sexual abuse may lead to HIV transmission and others sexually transmitted infections. The high level of positive attitude towards prevention of child sexual abuse in our study might be a result of good knowledge demonstrated by respondents.

The practices are the most important element in the prevention of child sexual abuse in the community. Despite the high level of knowledge and positive attitude, our study has shown low level of protective practices in relation to prevention of child sexual abuse. A possible explanation is that, poor practices among respondents could be due to parent's traditional norms, beliefs, taboos and rituals among the Sukuma tribe (Muganyinzi et al., 201). It is restricted to disclose such incidents among the Sukuma. It is shameful within the household to disclose sexual abuse incidence in the family as this may cause misunderstanding among relatives and /or friends. Unlike in our study, in Botswana and Swaziland, parents acknowledged the prevalence of child sexual abuse and further demonstrated their knowledge of the predisposing factors, perpetrators of the problem, and effects of sexual abuse on children (Mathoma et al., 2006). Behavioural change interventions are needed to bring about changes, so as to improve practices for prevention of child sexual abuse in the community (Herbert et al.,2002).

The results of this study should be interpreted with caution, because the study was only done in Shinyanga district which is one among many districts in Tanzania. Moreover, study respondents might have attempted to portray themselves in a favourable image by providing answers that "unrealistically" indicated high level of knowledge, positive attitude and good practices about prevention of child sexual abuse. Nevertheless, since the study respondents were randomly selected, the findings shed light on parents' knowledge, attitude and practices about prevention of child sexual abuse in the larger population of Shinyanga district.

In conclusion, the results of this study have shown that majority of parents in Shinyanga District of Tanzania were knowledgeable and had positive attitude about their responsibility in prevention of child sexual abuse. However, the level of parents' practice in relation to prevention of child sexual abuse was low. Therefore, in order to bridge the knowledge practice gap identified 
in this study, it is recommended that (i) more emphasis on practices towards prevention of child sexual abuse should be included in community education programmes; (ii) parents should be encouraged to educate their children, not to let someone touch their genitals or leave their homes in the late evenings without being escorted by an adult; and (iii) parents should be encouraged to discourage their children from accepting presents/gifts from strange people. It is equally important that emphases on community involvement in fighting against the problem is promoted through appropriate education programmes. Enforcement of the laws that protect children against sexual abuse to successfully curb the problem needs to be equally emphasized. Further studies are needed on approaches for enhancing parental involvement in prevention of child sexual abuse in the Tanzanian communities.

\section{Acknowledgements}

The authors thank the Ministry of Health, Community Development, Gender, Elderly and Children and Shinyanga Regional Administrative Secretary for their financial support. The Shinyanga District Executive Director is thanked for the permission to conduct the study.

\section{References}

Abeid, M., Muganyinzi, P., Olsson, P., Darj, E. \& Axemo, P. (2014) Community perceptions of rape and child sexual abuse: a qualitative study in rural Tanzania. BMC International Health and Human Rights14:23

Babatsikos, G. (2010) Parents' knowledge, attitudes, and practices about preventing child sexual abuse: A literature review. Child Abuse Review 19, 107-129.

Bensley, L., van Eenwyk, J. \& Simmons K. (2000) Self-reported childhood sexual and physical abuse and adult HIV-risk behaviors and heavy drinking. American Journal of Preventive Medicine18, 151-158.

Chen, J. Q., \& Chen, D. G. (2005). Awareness of child sexual abuse prevention education among parents of Grade 3 elementary school pupils in Fuxin City, China. Health Education Research, 20(5), 540-547.

Chen, J. Q., Dunne, M. P., \& Han, P. (2007). Prevention of child sexual abuse in china: knowledge, attitudes, and communication practices of parents of elementary school children. Child Abuse \& Neglect, 31(7), 747-755.

Cochran, W. G. (1977) Sampling techniques (3rd ed.). New York: John Wiley \& Sons.

Garcia-Moreno, C. Jansen, H.A.M., Elisberg M., Heise, L. \& Watts, C. (2005). WHO Multi-Country Study on Women's Health and Domestic Initial results on prevalence. Genetics, 151(1), 277-83

Hébert, M., Tourigny, M., Cyr, M., McDuff, P., Joly, J. (2009) Prevalence of childhood sexual abuse and timing of disclosure in a representative sample of adults from the province of Quebec. Canadian Journal of Psychiatry 54, 631-636.

Kisanga, F., Mbwambo, J., Hogan, N., Nystrom, L., Emmelin, M., Lindmark, G. (2010). Perceptions of child sexual abuse-a qualitative interview study with representatives of the socio-legal system in urban Tanzania. Journal of child sexual abuse, 19(3), 290-309.

Kisanga, F., Nyström, L., Hogan, N., Mbwambo, J., Lindmark, G., Emmelin, M. (2010) Perceptions of child sexual abuse-a qualitative interview study with representatives of the socio-legal system in urban Tanzania. Journal of Child Sexual Abuse 19, 290-309.

Kisanga, F., Nyström, L., Hogan, N., Emmelin, M.. (2013). Parents' experiences of reporting child sexual abuse in urban Tanzania. Journal of Child Sexual Abuse: Research, Treatment, \& Program Innovations for Victims, Survivors, \& Offenders, 22, 481-498.

Laisser, R.M., Lugina, H.l., Lindmark, G., Nyström, L., Emmelin, M. (2009) Striving to make a difference: health care worker experiences with intimate partner violence clients in Tanzania. Health Care Women International 30, 64-78. 
Laisser, R.M., Nyström, L., Lugina, H.I., Emmelin, M. (2011) Community perceptions of intimate partner violence - a qualitative study from urban Tanzania. BMC Women's Health 11: 13-10.

Lalor, K. (2004) Child sexual abuse in sub-Saharan Africa: a literature review. Child Abuse \& Neglect 28, 439-460.

Mathoma, A.M., Maripe-Perera, D.B., Khumalo, L.P., Mbayi, B.L., Seloilwe, E.S. (2006) Knowledge and perceptions of parents regarding child sexual abuse in Botswana and Swaziland. Journal of Pediatrics Nursing 21, 67-72

Muganyinzi, P.S., Nyström, L., Axemo, P., Emmelin, M. (2011) Managing in the contemporary world: rape victims' and supporters' experiences of barriers within the police and the health care system in Tanzania. Journal of Interpersonal Violence 20, 1-23.

Putnam, F.W. (2003) Ten-year research update review: Child sexual abuse. Journal of American Academy of Child and Adolescent Psychiatry 42, 269-278.

Ritchter, L., Komárek, A., Desmond, C., Celentano, D., Morin, S., Sweat, M., Chariyalertsak, S., Chingono, A., Gray, G., Mbwambo, J. \& Coates, T. (2014) Reported Physical and Sexual Abuse in Childhood and Adult HIV Risk Behaviour in Three African Countries: Findings from Project Accept (HPTN-043). AIDS Behaviour 18, 381-389.

Singh, M.M., Parsekar, S.S. \& Nair, S.N. (2014) An Epidemiological Overview of Child Sexual Abuse. Journal of Family Medicine and Primary Care 3: 430-435.

Waterston, T. \& Mok, J. (2008) Violence against children: the UN report. Archives of Disease in Childhood, 93(1), 85-88.

WHO (2000) Violence Against Women and HIV/AIDS: Setting the Research Agenda. Meeting Report. Geneva: World Health Organization.

WHO (2003) Guidelines for Medicolegal Care for Victims of Sexual Violence. World Health Organization. Available from: http://www.who.int/publications/2004/924154628x.pdf .

WHO (2014) Child maltreatment. World Health Organization, Geneva. Available from: http://www.who.int/topics/child_abuse/en/

Wolak, J., Finkelhor, D., Mitchell, K.J., Ybarra, M. (2008) Online "predators" and their victims: Myths, realities, and implications for prevention and treatment. American Psychologist63, $111-128$. 